
\title{
R Research Sourare \\ Identification of Markers for Root Traits Related to Drought Tolerance Using Traditional Rice Germplasm
}

Harendra Verma ( $\square$ harendraicar@gmail.com )

ICAR Research Complex for NEH Region: ICAR Research Complex for North Eastern Hill Region https://orcid.org/0000-0003-4226-7662

R. N. Sarma

Assam Agricultural University Faculty of Agriculture

Original article

Keywords: Root traits, drought tolerance, SSR marker, rice and GWAS

Posted Date: February 8th, 2021

DOI: https://doi.org/10.21203/rs.3.rs-163605/v1

License: (c) (i) This work is licensed under a Creative Commons Attribution 4.0 International License.

Read Full License 


\section{Abstract}

Background: Drought is one of the important constraints affecting rice productivity worldwide. The vigorous shoot and deep root system help to improve drought resistance. In present era, genome-wide association study (GWAS) is the preferred method for mapping of QTLs for complex traits such as root and drought tolerance traits. In the present study, 114 rice genotypes were evaluated for various root and shoot traits under water stress conditions. All the genotypes were genotyped using 65 SSR markers covering all 12 chromosomes for the identification of various QTLs for root and shoot traits using MLM $(\mathrm{Q}+\mathrm{K})$ model in GWAS.

Results: All genotypes showed a significant amount of variation for various root and shoot traits. Correlation analysis revealed that high dry shoot weight and fresh shoot weight is associated with root length, root volume, fresh root weight and dry root weight. A total of 11 significant marker-trait associations were detected for various root, shoot and drought tolerance traits with the coefficient of determination $\left(\mathrm{R}^{2}\right)$ ranging from $18.99 \%$ to $53.41 \%$. Marker RM252 and RM212 showed association with three root traits which suggests their scope for improvement of root system in rice improvement breeding programmes. In the present study a novel QTL was detected for root length associated with RM127, explaining $19.30 \%$ of variation.

Conclusion: The marker alleles with increasing phenotypic effects for root and drought-tolerant traits can be exploited for improvement of root and drought tolerance traits using marker-assisted selection.

\section{Introduction}

Drought is the major abiotic stress that deleteriously affects rice productivity in the rainfed ecosystem (Kumar et al. 2020). In Asia, around 42 million hectares of rice cultivation out of total 163 million hectare rice cultivation is negatively affected by drought and this situation is worsening under the regime of climate change which further may likely to increase moisture stress intensity, duration and frequency (Yang et al. 2019; IPPC, 2014, Trenberth, 2014). Drought stress significantly reduces rice yield from 25$50 \%$ (Zhang et al. 2018; Daryanto et al. 2017) and causes an economic loss of \$37 billion (Kim et al. 2019). Reduced rice yield poses threats to global food security and sustainable development (Kim et al. 2020; Zhang et al. 2018, Ahmadi et al. 2014). The ceiling in rice productivity has been observed, which indicates the inadequacy to meet the future rice demand of the ever-growing population. Therefore there is a need to improve the productivity of rice cultivated in drought-prone areas. This has necessitated the development of drought-tolerant varieties to combat the moisture stress problem. Breeding for the development of drought-tolerant variety is the greatest challenge and priority.

Rice productivity in rainfed areas of the world can be enhanced in sustainable ways with genetic improvement of drought tolerance and root traits (Dixit et al. 2014; Palta and Yang, 2014). The root system is the foremost important plant organ which sense and responds to soil moisture stress and helps in the absorption of various nutrients and water from the soil for normal plants growth and development 
(Canales et al. 2019; Wasaya et al. 2018; Comas et al. 2013; Uga et al. 2013). Various root characteristics help in maintaining the plant productivity under drought are long specific root length, small fine root diameter and considerable root length density in deeper soil horizons, where an ample amount of moisture is available (Verma et al. 2019; Uga et al. 2015; Comas et al. 2013). Among rice genotypes, huge genetic variation is exists for root depth and various root traits (Verma et al. 2019). However, little progress has been made in characterizing the genetic determinants of root traits in relation to drought tolerance. Genetic improvement of root traits through conventional breeding is challenging and limited because roots are underground parts and screening is highly labor-intensive and difficult to use in large mapping populations. A study related to the detection of QTLs associated with root traits under water stress and drought tolerance using rice genotypes from North East India has not been carried out, which provides the opportunities for GWAS to supplement the drought tolerance improvement breeding. The use of molecular markers is the best tool to support phenotypic selection. Identification of drought-related QTLs (qDTY1.1) for grain yield (Vikram et al., 2011), Dro1 QTL (Uga et al., 2011) for root angle and their use in marker-assisted breeding is a hope to develop high yielding drought-tolerant rice varieties. QTLs associate with root traits and drought tolerance have been identified in rice and successfully introgressed using marker-assisted technology into rice elite breeding lines for improvement of root traits and development of drought-tolerant variety (Muthu et al. 2020; Anyaoha et al. 2019; Dharmappa et al. 2019; Dixit et al. 2017). Marker-assisted breeding (MAB) can improve the efficiency of plant breeding through the precise transfer of genomic regions of interest and fast recovery of the recurrent parent genome in lesser time as compared to conventional breeding methods (Wijerathana, 2015). Therefore, the identification of DNA markers associated with root traits and drought tolerance traits and their use in marker-assisted selection is the best tool to relieve this bottleneck.

The use of identified markers linked to a particular QTL using bi-parental mapping population is limited to a population of a specific cross and requires validation in a new population. The estimated effect of QTLs are also inconsistent in the different genetic background (Bernardo, 2008; Bernier et al. 2009) and poor linkage between QTLs and markers limits their use in MAB (Haong et al. 2019; Korte and Farlow 2013; Swamy et al. 2017). Therefore to circumvent the limitation of QTL mapping, GWAS are considered as a potentially powerful approach for mapping causal genes with modest effects (Hirschhorn and Daly, 2005). The GWAS utilizes the broader genetic variations with wider background for marker traits association and identified markers have a strong linkage with traits. Identification of markers associated with root traits and drought tolerance in diverse rice landraces set will help in stable estimation of the genetic basis and their application may increase the improvement of root and drought tolerance.

North-Eastern India is one of the hot spots of rice genetic resources in the world (Myers N. 1988). The upland rice cultivated from March to July in this region is known agronomically as "aus/ahu" rice. Recently, based on genome sequence information, aus subpopulation is identified as distinct subpopulation of O. sativa species (Travis et al. 2015, Civáň et al. 2015) and suggested that aus cultivars evolved from a distinct population of the annual Oryza nivara found in NE India, Bangladesh and Northern Myanmar (Kim et al. 2016, Norton et al. 2018). The upland landraces of rice present in northeast India are drought-tolerant, photoperiod insensitive has better root system and resistant to diseases 
(Verma et al. 2020; Verma et al. 2019 and Umakanth et al. 2017). For example, Aus 196, an improved drought-tolerant cultivar belongs to aus subspecies and originated from Eastern India (McNally et al. 2009; Yadav et al. 2019). Drought-tolerant genotypes 'Banglami' and 'Inglongkiri' were identified from Assam (Verma et al. 2019 and http://dbtaau.ac.in/allele.html). Therefore, it is expected that the germplasm from North-Eastern India might provide new genes/alleles for the improvement of drought tolerance via a better root system.

Thus in the present study, an attempt has been made to detect the significant major QTLs associated with root traits and drought tolerance through GWAS using Northeast India traditional rice germplasm. So that, identified candidate genes can be used for the improvement of drought tolerance in rice using MAB technology.

\section{Materials And Methods}

\section{Plant Materials and Phenotypic Evaluation}

The present study material consists of 114 rice genotypes of Northeast India involving Ranjit, IR-64 and Manohar Sali HYVs. Pure and healthy seeds of 114 rice landraces were obtained from Regional Agricultural Research Station (RARS) Titabar farm of Assam Agricultural University, Jorhat. These rice genotypes were directly sown in moist soil in three replications and evaluated for various root and drought tolerance traits at reproductive stage in PVC pipes using completely randomized block design (CRBD design under a rain shelter at Instrumental cum Research (ICR) farm of Assam Agricultural University, Jorhat. All genotypes were phenotyped for root length (RL), root volume (RV), fresh root weight (FRW), dry root weight (DRW), root angle (RA), bottom root number (BRN), peripheral root number (PRN), shoot length (SL), dry shoot weight (DSW), fresh shoot weight (FSW), root to shoot ratio (RSR), ratio of deep rooting (RDR), leaf rolling score (RLS) and drought recovery (DR) (Table 1). Drought was induced by withdrawing the life-saving irrigation 13 days after sowing (DAS). The observation for drought tolerance was recorded during noon hours at 32 and 34 days after withdrawal of life-saving irrigation (DAWW) when the soil moisture content was around 7-8\% (W/V) and susceptible check (IR64 and Ranjit) showed complete drought stress symptoms using "Standard Evaluation System for Rice (SES)" (IRRI, 2002). The soil moisture status was determined by using the gravimetric method (Reynolds, 1970). The root length, shoot length, fresh root weight and shoot weight data of 46-day-old plants of stress experiment was recorded using PVC pipes following the standard method. Root dry weight and shoot dry weight were recorded after consistent drying of plant samples for 7 days at $80^{\circ} \mathrm{C}$. The basket method of Uga et al. (2011) was used to measure root angle, bottom root number and peripheral root number. Baskets were filled with sieved soil free of the root of weeds and no fertilizer was applied.

\section{SSR Genotyping}

A total of 170 SSR markers involving 30 gene-specific markers related to root and aquaporins, covering all 12 chromosomes were assessed for genotyping of 114 rice genotypes. Based on prominent distinguishable banding patterns and polymorphism 65 SSR markers including 4 gene-specific markers 
were chosen out of 170 SSR markers for genotyping. The genetic sequence of genes related to root traits and drought tolerance factors were downloaded from http://rapdb.dna.affrc.go.jp/ and http://rice.plantbiology.msu.edu/. Gene-specific primers were designed using Primer 3 software. SSR marker sequences, annealing temperature and chromosomal locations were obtained from the GRAMENE database.

Genomic DNA was isolated from fresh leaves of each genotype included in the present study following the protocol of Plaskhe et al. (1995) with slight modification. The quality of DNA was determined by comparing the genomic DNA with uncut-lambda DNA marker in $1 \%$ agarose gel and; quantity was determined using nano-drop reading at $260 \mathrm{~nm}$. The final concentration of DNA was adjusted to $30 \mathrm{ng} / \mu \mathrm{l}$ for PCR reaction. The amplification conditions were based on the procedure of Panaud et al. (1996). The PCR reaction volume was $10 \mu \mathrm{l}$. The PCR reaction mixture of $10 \mu \mathrm{l}$ consists of $0.4 \mathrm{mMdNTPs}, 4 \mathrm{mM}$ of $\mathrm{MgCl} 2,150 \mathrm{mM}$ of Tris- $\mathrm{HCl}, 10$ pmoles of forward and reverse primer and $0.05 \mathrm{U}$ Taq polymerase with 30 ng of DNA. The reagents were mixed thoroughly and then placed in a Thermal Cycler (PCR Gene AMP® 2400, Applied Biosystems, USA) for cyclic amplification using the amplification programme Step 1 (Initial denaturation) $94{ }^{\circ} \mathrm{C}$ for $5 \mathrm{~min}$. Step 2 (Denaturation) $94{ }^{\circ} \mathrm{C}$ for $1 \mathrm{~min}$. Step 3 (Annealing) $32{ }^{\circ} \mathrm{C}$ for $1 \mathrm{~min}$. Step 4 (Extension) $72{ }^{\circ} \mathrm{C}$ for $1 \mathrm{~min}$. Step 5 (Final extension) $72{ }^{\circ} \mathrm{C}$ for $5 \mathrm{~min}$. Step 6 (Storage) $4{ }^{\circ} \mathrm{C}$ for infinity. Steps 2, 3 and 4 were repeated 35 times.

\section{Gel Electrophoresis, Photography and Allele Scoring}

Amplified alleles were separated based on their size using 3\% agarose gel and 1X TBE buffer in the horizontal electrophoresis tank, after this the gel image was digitally documented in Gel Documentation System (UVP, UK). The size of distinct amplified bands was measured in base pair by comparing with the band size of 100 bp ladder (GeNel Company) with IR-36 as molecular weight reference.

\section{Data Analysis}

The mean of root and drought tolerance data recorded from genotypes were subjected to analysis of variance (ANOVA), genotypic coefficient of variation (GCV), phenotypic coefficient of variation (PCV), broad sense heritability and genetic advance as $5 \%$ of the mean (GA) using SPAR 2.0 software (Sangeetha et al. 2008). R software packages corrplot (Wei and Simko 2017) and RColorBrewer (Neuwirth, E. 2014) were used for calculation and visualization of the Pearson's correlation. Association analysis between marker loci and phenotypic traits was performed in all trials using TASSEL (Trait Analysis by association, Evolution and Linkage) software version 4.0 (Bradbury et al. 2007) after accounting for the gross level population structure (Q) in GLM analysis. The $Q+K$ (kinship) model was used in the MLM analysis with P3D algorithm (Zhang et al. 2010). It has been reported that the $Q+K$ model reduces the false positive associations (Rincent et al. 2014). Hence, the results of MLM which uses the $\mathrm{Q}+\mathrm{K}$ model are reported in the study. The marker $\mathrm{P}$ value $(0.001)$ was used to determine the significance of each marker-trait association. 


\section{Results}

\section{Root, Shoot and Drought Tolerance Traits}

The mean values of the root, shoot and drought tolerance traits and genetic parameters of 114 rice genotypes are given in Table 1. In water stress condition, among the genotypes, the highest root length was recorded in Inglongkiri $(25.50 \mathrm{~cm})$ while the lowest root length $(7.00 \mathrm{~cm})$ was recorded in Ranga Sali2 with an average root length of $12.60 \mathrm{~cm}$. The fresh root weight ranged from $0.09 \mathrm{~g}$ in Miren Killak to $8.57 \mathrm{~g}$ in Inglongkiri, with a mean fresh root weight of $0.70 \mathrm{gm}$. Similarly, dry root weight varied from 0.02 $\mathrm{g}$ for AS-69-70 to $2.49 \mathrm{~g}$ for Inglongkiri with an overall mean of $0.22 \mathrm{~g}$. Root volume ranged from $0.08 \mathrm{ml}$ for Ahu Joha to $8.65 \mathrm{ml}$ for Inglongkiri. The highest root angle was recorded in Kosamoni $\left(64^{\circ}\right)$ while the lowest root angle $\left(16^{\circ}\right)$ was recorded in Norin18/Patnai23 and Ranga Sali-2 with an average root angle of $47^{\circ}$. The wide range of variation for root length, root weight, root volume, root angle revealed the scope for selection for the development of genotypes with the better root system. The minimum periphery root number 7 was recorded in Norin 18/Patnai 23 while the maximum periphery root number 55 was recorded in Nepali Sali (55), with a mean of 22. The bottom root number ranged from 0 for Boga Gajep to 40 for As 193/1, with a mean of 11. Among genotypes, the highest root: shoot ratio was recorded in Dusri Ahu (0.49) and the lowest root: shoot ratio recorded in searcher (0.14) and Kacher Sali (0.14), with a mean of 0.23. Highest ratio of deep rooting was recorded in As 193/1 (0.81) while the lowest ratio of deep rooting was recorded in Boga Gajep (0), with a mean of 0.34. Maximum bottom root number and highest ratio of deep rooting were observed in As 193/1, but it showed drought susceptible response based on leaf rolling score.

In stress condition, the maximum shoot length was recorded in Horin Kajuli $(94.33 \mathrm{~cm})$ while lowest shoot length was recorded in Lachit and Raja Ahu $(30 \mathrm{~cm})$ with a mean shoot length of $56.03 \mathrm{~cm}$. Genotypes having long shoot length showed long root system, for example, genotypes ARC10372, Banglami, Inglongkiri, December Sali-1, Goruntia Ahu, Horin Kajuli, Hafa Ahu and Ikora Guni showed long shoot length and long root system. Selection of these genotypes having tall and thick stem might help in increasing root length and drought tolerance. Fresh shoot weight ranged from $0.15 \mathrm{gm}$ for Miren Killak to Horin Kajuli $10.03 \mathrm{gm}$. Fresh shoot weight had an overall mean of $1.86 \mathrm{gm}$ and Horin Kajuli significantly differed from all other genotypes for fresh shoot weight. Genotypes showing high long shoot weight showed high long root weight. Among the genotypes, dry shoot weight ranged from $0.03 \mathrm{gm}$ for Miren Killak to $2.82 \mathrm{gm}$ for Inglongkiri, with a mean dry weight of $0.45 \mathrm{gm}$. Inglongkiri was significantly superior for dry shoot weight among all genotypes. Among 114 genotypes under study, nine genotypes showed a leaf rolling score of 0 indicating drought tolerant and 18 genotypes showed a leaf rolling score of 5 and 3 suggesting moderately drought tolerant. Thirteen genotypes showed the leaf rolling score of 7 which indicated moderate susceptibility of genotypes towards drought and 74 genotypes showed leaf rolling scoring of 9 which indicated susceptibility towards drought.

In the present study material Inglongkiri, Banglami, ARC10372, Bizor and Horin Kajuli are the promising genotypes that showed better root system and drought tolerance response to be used in the breeding 
programme for improvement of drought tolerance. Improvement of the root system and drought tolerance would be the key to develop elite rice varieties suitable for the water-saving farming system.

\section{Genetic variability for root, shoot and drought tolerance traits}

The study of genetic variation and identification of promising genotypes with the desired root system might help breeding programmes in the development of drought-tolerant rice. The estimate of the genotypic and phenotypic coefficient of variation, heritability in broad sense and expected genetic advance as a percentage mean expected at $5 \%$ for the characters are presented in Table 1 . In all these characters' understudy, GCV had a close correspondence with PCV along with high heritability estimates indicating less influence of environmental factors and predominance of an additive gene effect. The analysis revealed the existence of a very high genotypic coefficient of variation for all parameters.

Broad sense heritability was found higher for all characters. Maximum broad sense heritability recorded for recovery $(98.90 \%)$ followed by drought scores at different days after withdrawal of water $(98.80 \%)$ and shoot length $(93.50 \%)$ respectively. Genetic advance as a percentage of mean was observed higher (> than $42 \%$ ) for all the characters. The maximum genetic advance was observed for fresh root weight (238.24\%) followed by dry root weight (194.19\%) and recovery $(185.00 \%)$, respectively. All these characters exhibited high genetic gain along with high heritability indicating a preponderance of additive gene action. Recovery, fresh root weight, dry root weight, fresh shoot weight, dry shoot weight and root volume trait are the best to use in breeding considering GCV, heritability and genetic advance. The present findings for root system variation suggested the possibility for the development of variety with a better root system having drought tolerance using the existing variability.

Table 1. Genetic variability of drought tolerance score, root and shoot traits in rice 


\begin{tabular}{|c|c|c|c|c|c|c|c|c|}
\hline \multirow{2}{*}{$\begin{array}{l}\text { Parameter } \\
\text { Traits }\end{array}$} & \multicolumn{2}{|c|}{ Range } & \multirow{2}{*}{$\begin{array}{l}\text { Mean } \pm \\
\text { SEm }\end{array}$} & \multirow{2}{*}{$\begin{array}{l}C D \\
5 \%\end{array}$} & \multirow[t]{2}{*}{ GCV } & \multirow[t]{2}{*}{ PCV } & \multirow{2}{*}{$\begin{array}{l}h^{2} \text { (Broad } \\
\text { Sense) }\end{array}$} & \multirow{2}{*}{$\begin{array}{l}\text { GA as } \% \text { of } \\
\text { Mean (5\%) }\end{array}$} \\
\hline & Mini. & Max. & & & & & & \\
\hline $\begin{array}{l}\text { DS } 32 \\
\text { DAW }\end{array}$ & 0.04 & 0.95 & $\begin{array}{l}0.83 \pm \\
0.02\end{array}$ & 0.05 & 27.83 & 28.13 & 0.98 & 56.70 \\
\hline $\begin{array}{l}\text { DS34 } \\
\text { DAW }\end{array}$ & 0.04 & 0.95 & $\begin{array}{l}0.90 \pm \\
0.01\end{array}$ & 0.03 & 20.58 & 20.71 & 0.99 & 42.14 \\
\hline Recovery & 0.04 & 0.95 & $\begin{array}{l}0.44 \pm \\
0.02\end{array}$ & 0.07 & 90.32 & 90.84 & 0.99 & 185.00 \\
\hline $\mathrm{RL}(\mathrm{cm})$ & 7.00 & 25.50 & $\begin{array}{l}12.60 \pm \\
0.54\end{array}$ & 1.49 & 25.20 & 26.26 & 0.92 & 49.84 \\
\hline $\mathrm{SL}(\mathrm{cm})$ & 30.00 & 94.33 & $\begin{array}{l}56.03 \pm \\
2.01\end{array}$ & 5.6 & 23.54 & 24.35 & 0.94 & 46.89 \\
\hline FRW (gm) & 0.07 & 8.57 & $\begin{array}{l}0.70 \pm \\
0.17\end{array}$ & 0.47 & 122.05 & 128.80 & 0.90 & 238.24 \\
\hline DRW (gm) & 0.02 & 2.49 & $\begin{array}{l}0.22 \pm \\
0.09\end{array}$ & 0.25 & 111.22 & 131.22 & 0.72 & 194.19 \\
\hline FSW (gm) & 0.15 & 10.03 & $\begin{array}{l}1.87 \pm \\
0.36\end{array}$ & 0.99 & 86.83 & 92.92 & 0.87 & 167.12 \\
\hline DSW (gm) & 0.03 & 2.82 & $\begin{array}{l}0.45 \pm \\
0.12\end{array}$ & 0.34 & 82.31 & 94.56 & 0.76 & 147.61 \\
\hline $\mathrm{RV}(\mathrm{ml})$ & 0.07 & 8.65 & $\begin{array}{l}1.20 \pm \\
0.35\end{array}$ & 0.99 & 77.77 & 93.01 & 0.70 & 133.94 \\
\hline $\mathrm{RA}\left(\left(^{\circ}\right)\right.$ & 16.00 & 92.00 & $\begin{array}{l}49.66 \pm \\
4.27\end{array}$ & 11.9 & 29.05 & 32.64 & 0.79 & 53.24 \\
\hline PRN & 6.67 & 55.00 & $\begin{array}{l}21.96 \pm \\
2.64\end{array}$ & 7.36 & 36.18 & 41.76 & 0.75 & 64.57 \\
\hline BRN & 0.00 & 40.00 & $\begin{array}{l}11.10 \pm \\
1.68\end{array}$ & 4.68 & 41.52 & 49.09 & 0.72 & 72.33 \\
\hline RSR & 0.14 & 0.49 & $\begin{array}{l}0.23 \pm \\
0.01\end{array}$ & 0.03 & 28.17 & 29.38 & 0.92 & 55.65 \\
\hline RDR & 0.00 & 0.81 & $\begin{array}{l}0.34 \pm \\
0.04\end{array}$ & 0.11 & 30.00 & 36.35 & 0.68 & 51.00 \\
\hline
\end{tabular}

Mini.=minimum, Max.=maximum, $S E m=$ standard error of mean, $C D=$ critical difference, $h^{2}=$ heritability, $\mathrm{GA}=$ genetic advance, DS $32 \mathrm{DAW}=$ drought score 32 days after withdrawal of water, DS $34 \mathrm{DAW}=$ drought score 34 days after withdrawal of water, $R L=$ root length, $S L=$ shoot length, $F R W=$ fresh root weight, $\mathrm{DRW}=$ dry root weight, $\mathrm{FSW}=$ fresh shoot weight, $\mathrm{DSW}=\mathrm{dry}$ shoot weight, $\mathrm{RV}=$ root volume, $\mathrm{RA}=$ root angle, 
PRN=periphery root number, BRN=bottom root number, RSR=root to shoot ratio, RDR=ratio of deep rooting

\section{Interrelationship studies}

The interrelationship analysis is presented in Figure 1, and this analysis revealed that root length has a positive correlation with fresh root weight, dry root weight, fresh shoot weight, dry shoot weight and root volume. Selection for high dry shoot weight and fresh shoot weight help in the improvement of root length, root volume, fresh root weight and dry root weight, which leads to improvement in drought tolerance.

Root volume had a positive correlation with fresh root weight, dry root weight, dry shoot weight, fresh shoot weight and shoot length. Fresh root weight was positively correlated with dry root weight, dry shoot weight, fresh shoot weight and root length.

The ratio of deep rooting (RDR) showed a positive correlation with the number of bottom root number at the genotypic and phenotypic level, which is obvious because RDR is the proportion of the total number of roots penetrating the lower part of the mesh to the total number of roots penetrating the whole mesh. Therefore, as there is an increase in the number of bottom root numbers there will be an increase in RDR. Root: shoot ratio had a negative correlation with shoot length both at the genotypic and phenotypic level which is also obvious, as there is an increase in shoot length there will be a decrease in root/shoot ratio.

\section{Marker-Trait Association Analysis}

Population structure may lead to a spurious association between marker and traits. Therefore, to avoid spurious association genetic structure of the given population was identified using the software STRUCTURE version 2.3.4 (Verma et al. 2019). The Q matrix generated in structure analysis was used for the model-based general linear model (GLM) and mixed linear model (MLM) approach for association mapping. Marker trait association analysis using MLM model (mixed linear model) based on Q matrix generated in STRUCTURE and kinship matrix of TASSEL revealed a total of 11 associations at $P<0.0001$ for eight roots, shoot and drought sensitivity traits with $\mathrm{R}^{2}$ ranging from $18.99 \%$ to $58.11 \%$ under water stress situation without type 1 error (Table 2). In this study, both GLM and MLM tests showed different outcomes since GLM considers only population structure, whereas MLM uses both population structure and kinship for analyses.

One association was detected for recovery of $1^{\text {st }}$ leaf one day after irrigation on chromosome 9 by RM24390 explaining $18.99 \%$ of the variation. The marker RM212 located on chromosome 1 showed association with dry root weight, fresh root weight and root volume explaining $33.96 \%, 31.79 \%$ and $30.83 \%$ of the variation, respectively. The marker RM252 on chromosome 4 was associated with dry root weight, fresh root weight, root volume, dry shoot weight and fresh shoot weight explaining $58.11 \%$, $53.41 \%, 40.42 \%, 37.90 \%$ and $19.27 \%$ of the variance respectively. Single marker RM418 on chromosome 
7 was associated with root to shoot ratio with a variation of $23.27 \%$. The marker RM127 on chromosome 4 was associated with root length explaining $19.30 \%$ of the variation.

Table 2. Significant marker-trait associations for the various root, shoot and drought sensitivity related traits under water stress situation

\begin{tabular}{|llllll|}
\hline Trait & Marker Name & Chromosome & F value & P value & R $^{2}$ \\
\hline Leaf recovery 55 DAS & RM24390 & 9 & 9.81 & $1.21 \mathrm{E}-04$ & 0.1899 \\
\hline Dry shoot weight & RM252 & 4 & 10.10 & $5.76 \mathrm{E}-07$ & 0.3790 \\
\hline Fresh shoot weight & RM252 & 4 & 5.08 & $8.81 \mathrm{E}-04$ & 0.1927 \\
\hline Root: Shoot ratio & RM418 & 7 & 8.42 & $4.48 \mathrm{E}-05$ & 0.2327 \\
\hline Root volume & RM212 & 1 & 17.76 & $2.15 \mathrm{E}-07$ & 0.3083 \\
\hline Root volume & RM252 & 4 & 11.64 & $7.13 \mathrm{E}-08$ & 0.4042 \\
\hline Root length & RM127 & 4 & 6.77 & $3.17 \mathrm{E}-04$ & 0.1930 \\
\hline Dry root weight & RM212 & 1 & 18.88 & $9.28 \mathrm{E}-08$ & 0.3396 \\
\hline Dry root weight & RM252 & 4 & 16.16 & $2.33 \mathrm{E}-10$ & 0.5811 \\
\hline Fresh root weight & RM212 & 1 & 17.85 & $2.00 \mathrm{E}-07$ & 0.3179 \\
\hline Fresh root weight & RM252 & 4 & 14.99 & $9.58 \mathrm{E}-10$ & 0.5341 \\
\hline
\end{tabular}

\section{Allelic Effect of Linked Markers}

The allelic effects, in terms of band size in bp, of different linked markers are depicted in the boxplot (Fig. 2). The RM24390 markers is associated with leaf recovery 55 DAS and two alleles were detected. The allele of 80 bp of RM24390 is associated with an increasing phenotypic effect by $10.7 \%$ on leaf recovery, whereas, the allele of $90 \mathrm{bp}$ is associated with a decrease of leaf recovery by $25.24 \%$.

The marker RM252 is associated with fresh shoot weight, dry shoot weight, root volume, dry root weight and fresh root weight. Three alleles were detected for RM252 marker. The allele of 170 bp of RM252 is associated with an increasing phenotypic effect of fresh shoot weight by $0.76 \mathrm{~g}$, dry shoot weight by $0.19 \mathrm{~g}$, root volume by $0.16 \mathrm{ml}$ and fresh root weight by $0.16 \mathrm{~g}$, whereas the allele of $155 \mathrm{bp}$ associated with the decrease of fresh shoot weight by $0.40 \mathrm{~g}$, dry shoot weight by $0.9 \mathrm{~g}$, root volume by $0.2 \mathrm{ml}$ and fresh root weight by $0.14 \mathrm{~g}$. The marker RM212 is associated with root volume, fresh root weight and dry root weight and two alleles were detected. The allele of $125 \mathrm{bp}$ of RM212 is associated with increasing phenotypic effect of root volume by $0.05 \mathrm{ml}$, dry root weight by $0.04 \mathrm{~g}$, dry root weight by $0.005 \mathrm{~g}$, whereas the allele of $145 \mathrm{bp}$ of RM212 associated with the decrease of root volume by $0.07 \mathrm{ml}$ dry weight by $0.1 \mathrm{~g}$ and dry root weight by $0.002 \mathrm{~g}$. The marker RM418 is associated with root to shoot ratio and two alleles were detected. The allele of $250 \mathrm{bp}$ of RM418 is associated with increasing phenotypic effect of root to 
shoot ratio by 0.002 , whereas the allele of $300 \mathrm{bp}$ of RM418 is associated with decreasing phenotypic effect of root to shoot ratio by 0.0004 . The marker RM127 was associated with root length and two alleles were detected. The allele of $230 \mathrm{bp}$ of RM12 is associated with increasing phenotypic effect of root length by $0.11 \mathrm{~cm}$, whereas the allele of $270 \mathrm{bp}$ is associated with a decrease of root length by $0.16 \mathrm{~cm}$.

\section{Discussion}

Identification and mapping of molecular markers significantly associated with traits of interest can help in the genetic improvement of cultivars through the deployment of marker-assisted breeding (MAB). MAB has enormous potential to transfer desirable traits from donor parent to recipient parent in less time through deployment of molecular markers associated with a trait of interest (Yadav et al. 2019). The recent advances in molecular breeding tools and techniques have been very useful in understanding the genetic basis of complex traits to identify major genes/QTLs for use in rice breeding (Das et al. 2017, Swamy et al. 2017). Several major drought yield QTLs such as qDTY1.1, qDTY2.1, qDTY2.2, qDTY3.1, qDTY3.2, qDTY9.1 and qDTY12.1 with consistent effect have been identified and introgressed into elite varieties through marker-assisted selection for enhancement of drought tolerance. But, most of the QTL studies were on biparental or multiparent populations are limited by the allelic diversity within the selected parents and the amount of recombination that occurs during the creation of the RIL population places a limit on the mapping resolution (Balasubramanian et al. 2009) which leads to detection of genes/QTL far from genetic markers. When these QTLs are introgressed using genetic markers into elite varieties they may segregate or recombination may take place between marker and genes/QTL. Biparental mapping is time-consuming and may not be effective for moderate and small effects. Association mapping is more effective in the detection of more genes/alleles with higher resolution as compared to biparental analysis through the exploitation of historical recombination events at the population level. Association mapping is a powerful tool used for high-resolution mapping of quantitative traits such as yield and drought-related traits (Ibrahim et al. 2020, Zhu et al. 2008). Spurious associations due to hidden population structure were avoided by population structure analysis (Pritchard et al. 2000 and Yu et al. 2006).

The identification of QTLs affecting drought tolerance is a crucial step in understanding the genetic basis of drought, for the development of drought-tolerant cultivars. Genome-wide association mapping is a powerful approach to identify associations between traits of interest and genetic markers using diverse genotypes. In GWAS the entire genome is to be assessed for trait-associated variants, rather than analyzing specific candidate genes (Agrama et al. 2007). The GWAS has been done for the identification of genes/QTLs for root traits related to drought tolerance, which is a crucial step in understanding the genetic basis of drought tolerance in relation to root traits for improvement of drought tolerance. The development of drought-tolerant variety is most important under the regime of climate change. The present study aimed to assess the genetic variation and identify markers for root, shoot traits under earlystage water stress using the GWAS approach. 


\section{Marker Trait Association}

A total of 5 SSR markers were significantly associated with root, leaf recovery and shoot traits under water stress. One association was detected for the marker RM24390 on chromosome 9 was associated with recovery of $2^{\text {nd }}$ leaf one day after irrigation on chromosome 9 by RM24390 and explaining 19.05\% of the variation. A promising QTL, $q D T Y_{9.1 B}$ was detected for grain yield under water stress associated with SSR marker interval between RM24350 (15.4 Mb) to RM24390 (15.9 Mb) (Dixit et al. 2012) and this QTL did not show a positive effect on grain yield under the irrigated situation. The present study also confirmed the presence of QTLs near RM24390 for drought tolerance and which needs further analysis, though no published report available on the presence of QTL for drought sensitivity traits on this chromosome.

The marker RM212 located on chromosome 1 showed association with dry root weight, fresh root weight and root volume explaining $33.96 \%, 31.79 \%$ and $30.83 \%$ of variance, respectively. The marker RM212 was associated with root volume (Qu et al. 2008), root dry weight (Xing et al. 2002) in Zh97/Ming63 RI lines thereby confirming the association of RM212 with root volume and dry root weight QTLs. Similarly, Kamoshita et al. (2002) reported QTLs for root depth, penetrated root thickness, deep root-to-shoot ratio, deep root dry weight, deep root per tiller, and deep root mass to be associated with RM212 on chromosome 1 in CT9993/IR62266 DH lines, which also confirmed the association of RM212 with the QTLs for dry root weight. RM212 was reported to be linked with plant height, panicle length, shoot biomass, straw yield and harvest index under water stress (Prince et al. 2015). Swamy et al. (2011) reported RM543-RM212 a small genetic distance of $0.27 \mathrm{~kb}$ associated with yield and drought tolerance in rice. Similarly, Kanagraj et al. (2010) reported that RM212 was associated with drought resistance traits. Henry et al. (2012) reported that RM212 is associated with yield in a drought situation in the cross of IR 64 and N-22 in rice. Gomez et al. (2010) reported RM212 to be associated with plant height and biomass under water stress. Zhao et al. (2008) found RM212 to be linked with stomatal conductance and transpiration rate under stress. Sabar et al. (2019) reported association of RM212-RM265 with plant height, the findings of Babu et al. (2003) suggested that RM212 was associated with RWC under drought stress. Salunkhe et al. (2011) reported that region RM212-RM302-RM8085-RM3825 on chromosome 1, harbours large effect QTLs for drought-resistance traits across several genetic backgrounds in rice. SSR Marker RM212 has been used in MAS for introgression of qDTY2.1 and qDTY1.1 QTLs for drought tolerance improvement in rice (Sandhu and Kumar, 2017). The present study corroborated those results confirming the presence of QTLs for fresh root weight, dry root weight, root volume and dry shoot weight linked to RM212. However, the presence of QTLs for many traits identified with RM212, the possibility of pleiotropic effect or a closely linked gene complex, needs further analysis with a high-density marker around this region.

Marker RM252 on chromosome 4 was associated with dry root weight, fresh root weight, root volume, dry shoot weight and fresh shoot weight explaining $58.11 \%, 53.41 \%, 30.83 \%, 37.90 \%$ and $19.27 \%$ of variance respectively. Zheng et al. (2000) reported RM252 to be associated with root thickness and root penetration ability. Singh et al. (2012) reported validation of RM252 associated with root thickness and 
penetrating ability under drought situation in rice recombinant inbred lines (RILs). The present investigation also confirmed the associations of RM252 with root traits under water stress situation as similar QTLs were identified previously. The present study also detected the association of RM252 with shoot traits, it might be due to the pleiotropic effects of this marker on root and shoot traits or colocalization of root and shoot traits. The correlation coefficient analysis also revealed the association of root and shoot traits. Therefore, further confirmation is required with a high-density marker around this region to ensure the pleiotropic effect or co-localization of markers for root and shoot traits on chromosome 4. The pleiotropic or co-localization of markers for root and shoot traits provide the opportunity to explore the collaborative development of root and shoot traits in rice (Zhao et al. 2019).

In the present study RM127 located on chromosome 4 was associated with root length explaining $19.30 \%$ of variation. This marker was identified to be linked to spikelet fertility in rice (Lanceras et al. 2004). Zhao et al. (2019) also reported root length QTL associated with RM1112 which is close to RM127 in indica rice species. Since, there is a dearth of information of any QTL for root length on chromosome 4, the QTL identified in the present study may be considered a novel for root length. Further analysis is required to validate the present findings.

One association was detected for root shoot: ratio on chromosome 7 by RM418 explaining $23.27 \%$ of variation. Zhao et al. (2019) reported the association of RM418 with overwintering germination ability. An et al. (2019) and Zheng et al. (2015) reported association with salt tolerance in rice. Association of RM418 were reported with grain quality traits such as paste viscosity (Xu et al. 2016) and protein content (Zhong et al. 2011) in rice. Guo et al. (2015) reported association of RM418 with rice blast tolerance. GWAS study on yield traits by Eizenga et al. (2019) suggested association of RM418 with days to heading in rice. However, no published report was available to corroborate the presence of a QTL for root:shoot ratio linked to RM418, this QTL might be considered as novel QTL for root:shoot ratio. But more experiments are needed to confirm the validity of the QTL for root: shoot ratio as detected in the study.

The marker alleles which showed increasing phenotypic effects for root and drought-tolerant traits can be exploited through marker-assisted selection for improving root and drought tolerance of elite varieties.

\section{Phenotypic Variation and Potential for Genetic Improvement}

In the present study, significant variation for various root, shoot, drought sensitivity scores and recovery scores among rice genotypes indicated the scope of improvement in these traits using diverse germplasm. Similarly, variation for root traits such as root length, root biomass, root volume, roots to shoot ratio and shoot traits among rice accessions was reported (Raju et al. 2016; Courtois et al. 2013; Henry et al. 2011).

Deep rooting has been an important trait under water stress to acquire water from deep moist soil profile to avoid drought stress (Henry et al. 2011; Gowda et al. 2011; Wasson et al. 2012; Lynch and Brown, 2012). Rice genotypes having a deep root system along with high root density and thick root system may 
improve the drought tolerance in upland rice (Abd Allah et al. 2010). Thus, the deep root system is thought to be a key factor in enhancing drought avoidance by crops (Kirkegaard et al. 2007). Therefore, improving root system architectures in terms of root depth and high penetration in deep soil layers would be an effective strategy to avoid adverse effects of drought on yield (de Dorlodot et al. 2007). Identified genotypes with long root system in the present study can be used as a donor in breeding rice genotypes with a long root system to confer drought tolerance. Broad sense heritability was higher for all characters studied which indicates the scope of root length improvement using diverse landraces. Phung et al. (2016) also reported high broad sense heritability for root length, root volume and root dry weight, shoot dry weight, root fresh weight, root to shoot ratio.

The correlation analysis revealed that drought sensitivity score have poor correlation with many root and shoot and traits. But deep and better root system has high degree of connection to drought avoidance (Uga et al. 2011; Henry et al. 2011; Gowda et al. 2011; Wasson et al. 2012). The present study showed lack of correlation between root traits and drought tolerance might be due to differences in genotypes present in the study, screening technique and environment in which experiments were conducted. To find out a clear picture of the interrelationship between drought tolerance and other drought tolerance attributes, path coefficient analysis was carried out which indicated the importance of root volume and dry shoot weight and root:shoot ratio traits in improving drought tolerance in rice. These results were in consonance with the findings of Comas et al. (2013) and Kashiwagi et al. (2005) who reported that increased root biomass, root length density and rooting depth are often considered to be primary drivers of drought avoidance.

\section{Conclusion}

Moisture stress is the major abiotic stress affecting rice productivity in rainfed areas. Rice productivity in moisture stress prone areas of the world can be improved in sustainable ways with improvement of drought tolerance and root traits at genetic level. In the present study, 11 significant marker-trait associations were detected for various root, shoot and drought tolerance traits. Marker RM252 showed association with five traits related to shoot and root traits and RM212 showed association three root traits which suggest their scope for improvement of five traits in rice improvement breeding programmes. The marker alleles with increasing phenotypic effects for root, shoot and drought-tolerant traits can be deployed for improvement of root, shoot and drought tolerance traits using marker-assisted selection.

\section{Declarations}

\section{Ethics approval and consent to participate}

Not applicable

\section{Consent for publication}

Not applicable 
Availability of data and material

The datasets generated during and/or analysed during the current study are available from the corresponding author on reasonable request.

\section{Competing interests}

The authors declare no competing interests.

\section{Funding}

Assam Agricultural University (AAU), Jorhat, Assam, India provided the funds to carry out this research work during PhD programme.

\section{Authors' contributions}

H.V. planned and executed the research. R.N.S. planned and helped in data analysis. All authors reviewed and approved the manuscript. The datasets generated during and/or analyzed during the current study are available from the corresponding author on reasonable request.

\section{Acknowledgements}

We acknowledge financial supports by the Assam Agricultural University (AAU), Jorhat (Assam) and thanks to the Regional Agricultural Research Station RARS Titabar farm of AAU, Jorhat, for providing rice germplasm to carry out this research. The first is grateful to the Department of Plant Breeding and Genetics, AAU, Jorhat for all help in PhD programme.

\section{Authors' information (optional)}

Dr. Harendra Verma presently working as Scientist in Plant Breeding and Genetics discipline at ICAR research complex for north east hill region, Nagaland Centre, Medziphema-797106, Nagaland (India)

Dr. RN Sarma working as professor in Plant Breeding and Genetics discipline at AAU Jorhat-785013, Assam (India). He has a vast experience in molecular rice breeding and genetics.

\section{References}

1. Kumar S, Dwivedi SK, Basu S, Kumar G, Mishra JS, Koley TK, Rao KK, Choudhary AK, Mondal S, Kumar S, Bhakta N, Bhatt BP, Paul RK, Kumar A (2020) Anatomical, agromorphological and physiological changes in rice under cumulative and stage specific drought conditions prevailed in eastern region of India. Field Crops Research 245:107658

2. Yang $X$, Wang $B$, Chen $L$ et al. (2019) The different influences of drought stress at the flowering stage on rice physiological traits, grain yield, and quality. Sci Rep 9:3742 
3. Intergovernmental Panel Climate Change (IPCC). Climate Change 2014: Synthesis Report. Contribution of Working Groups I, II and III to the Fifth Assessment Report of the Intergovernmental Panel on Climate Change 2014; Core Writing Team, Pachauri RK, Meyer LA, Eds., IPCC: Geneva, Switzerland, 151p

4. Trenberth KE, Dai A, Schrier GVD, Jones PD, Barichivich J, Briffa KR, Sheffield J (2014) Global warming and changes in drought. Nature Climate Change 4:17-22

5. Zhang J, Zhang S, Cheng M, Jiang H, Zhang X, Peng C, Lu X, Zhang M and Jin J (2018) Effect of Drought on Agronomic Traits of Rice and Wheat: A Meta-Analysis. Int J Environ Res Public Health 15:839

6. Daryanto S, Wang L, Jacinthe PA (2017) Global synthesis of drought effects on cereal, legume, tuber and root crops production: A review. Agric Water Manag 179:18-33

7. Kim W, lizumi T, Nishimori M, (2019) Global patterns of crop production losses associated with droughts from 1983 to 2009. J Appl Meteorol Climatol 1233-1244

8. Kim Y, Chung YS, Lee E, Tripathi P, Heo S, Kim KH (2020) Root Response to Drought Stress in Rice (Oryza sativa L.). Int J Mol Sci 21(4):1513

9. Ahmadi N, Audebert A, Bennett MJ, Bishopp A, de Oliveira AC, Courtois B, Diedhiou A, Diévart A, Gantet $P$, Ghesquière $A(2014)$ The roots of future rice harvests. Rice 7:29

10. Dixit S, Singh A, Kumar A (2014) Rice breeding for high grain yield under drought: a strategic solution to a complex problem, Int J Agron 2014:15

11. Palta JA, Yang J (2014) Crop root system behaviour and yield. Field Crops Res 165:1-4

12. Canales FJ, Nagel KA, Müller C, Rispail N and Prats E (2019) Deciphering root architectural traits involved to cope with water deficit in Oat. Front Plant Sci 10:1558

13. Wasaya A, Zhang X, Fang Q \& Yan Z (2018) Root phenotyping for drought tolerance: A review. Agronomy 8(11):241

14. Comas LH, Becker SR, Cruz VMV, Byrne PF, Dierig DA (2013) Root traits contributing to plant productivity under drought. Front Plant Sci 4:442

15. Uga Y, Sugimoto K, Ogawa S, Rane J, Ishitani M, Hara N, Kitomi Y, Inukai Y, Ono K, Kanno N, et al. (2013) Control of root system architecture by DEEPER ROOTING 1 increases rice yield under drought conditions. Nat Genet 45:1097-1102

16. Uga Y, Kitomi Y, Ishikawa S, Yano M (2015) Genetic improvement for root growth angle to enhance crop production. Breeding Science 65(2):111-19

17. Verma H, Borah JL, Sarma RN (2019) Variability assessment for root and drought tolerance traits and genetic diversity analysis of rice germplasm using SSR markers. Sci Rep 9:16513

18. Verma H, Devi K, Baruah AR, Sarma RN (2020) Relationship of root aquaporin genes, OsPIP1;3, OsPIP2;4, OsPIP2;5, OsTIP2;1 and OsNIP2;1 expression with drought tolerance in rice. Indian J Genet 80(1):50-57 
19. Vikram P, Swamy B, Dixit S, Ahmed HU, Cruz MTS, Singh AK, Kumar A (2011) qDTY 1.1 , a major QTL for rice grain yield under reproductive-stage drought stress with a consistent effect in multiple elite genetic backgrounds. BMC Genet 12:89

20. Muthu V, Abbai R, Nallathambi J, Rahman H, Ramasamy S, Kambale R, et al. (2020) Pyramiding QTLs controlling tolerance against drought, salinity, and submergence in rice through marker assisted breeding. PLoS One 15(1):e0227421

21. Anyaoha CO, Fofana M, Gracen V, Tongoona P, Mande S (2019) Introgression of Two Drought QTLs into FUNAABOR-2 Early Generation Backcross Progenies Under Drought Stress at Reproductive Stage, Rice Science, 26(1): 32í41

22. Dharmappa PM, Doddaraju P, Malagondanahalli MV, Rangappa RB, Mallikarjuna NM, Rajendrareddy SH, Ramanjinappa R, Mavinahalli RP, Prasad TG, Udayakumar M et al. (2019) Introgression of root and water use efficiency traits enhances water productivity: An evidence for physiological breeding in rice (Oryza sativa L.) Rice 12:14

23. Dixit S, Singh A, Sandhu N, Bhandari A, Vikram P, Kumar A (2017) Combining drought and submergence tolerance in rice: marker assisted breeding and QTL combination effects. Mol Breed $37: 143$

24. Wijerathna YMAM (2015) Marker Assisted Selection: Biotechnology Tool for Rice Molecular Breeding. Adv Crop Sci Tech 3:4

25. Bernier J, Kumar A, Venuprasad R, Spaner D, Verulkar S, Mandal NP, Sinha PK, Peeraju P, Dongre PR, Mahto RN, Atlin G (2009) Characterization of the effect of a QTL for drought resistance in rice, qtl12.1, over a range of environments in the Philippines and eastern India. Euphytica 166:207- 217.

26. Bernardo R (2008) Molecular Markers and Selection for Complex Traits in Plants: Learning from the Last 20 Years. Crop Sci 48:1649-1664

27. Hoang GT, Van Dinh L, Nguyen TT et al. (2019) Genome-wide Association Study of a Panel of Vietnamese Rice Landraces Reveals New QTLs for Tolerance to Water Deficit During the Vegetative Phase. Rice 12: 4

28. Korte A, Farlow A (2013) The advantages and limitations of trait analysis with GWAS: a review. Plant Methods 9:29

29. Swamy BPM, Shamsudin NAA, Rahman SNA, Mauleon R, Ratnam W, Sta Cruz MT, Kumar A (2017) Association mapping of yield and yield-related traits under reproductive stage drought stress in rice (Oryza sativa L.). Rice 10:21

30. Hirschhorn J, Daly M (2005) Genome-wide association studies for common diseases and complex traits. Nat Rev Genet6: 95-108

31. Myers N (1988) Threatened biotas: "hots spots" in tropical forests. Environmentalist. 8(3):187-208

32. Travis AJ, Norton GJ, Datta S, Sarma R, Dasgupta T, Savio FL, macaulay M, Hedley PE, McNally KL, Sumon MH, Islam MR, Price AH (2015) Assessing the genetic diversity of rice originating from Bangladesh, Assam and West Bengal. Rice 8(1):1-9 
33. Civán P, Craig H, Cox CJ, Brown TA (2015) Three geographically separate domestications of Asian rice. Nat Plants 1:15164.

34. Kim HJ, Jung J, Singh N, Greenberg A, Doyle JJ, Tyagi W, Chung J-W, Kimball J, Hamilton RS, McCouch SR (2016) Population dynamics among six major groups of the Oryza rufipogon species complex, wild relative of cultivated Asian rice. Rice 9:56

35. Norton GJ, Travis AJ, Douglas A, Fairley S, De Paiva Alves E, Ruang-areerate P, Naredo MEB, McNally KL, Hossain M, Islam MR and Price AH (2018) Genome Wide Association Mapping of Grain and Straw Biomass Traits in the Rice Bengal and Assam Aus Panel (BAAP) Grown Under Alternate Wetting and Drying and Permanently Flooded Irrigation. Front Plant Sci 9:1223

36. Umakanth B, Vishalakshi B, Kumar PS, Devi SJSR, Bhadana VP, Senguttuvel P, Kumar S, Sharma SK, Sharma PK, Prasad MS, Madhav MS (2017) Diverse rice landraces of North-East India enables the identification of novel genetic resources for Magnaporthe resistance. Front Plant Sci 8:1500

37. McNally K, Childs KL, Bohnert R, Davidson RM, Zhao K et al. (2009) Genome wide SNP variation reveals relationships among landraces and modern varieties of rice. Proc Natl Acad Sci 106: 1227312278

38. Yadav S. sandhu N. Singh V K, Catolos M and Kumar A (2019) Genotyping-by-sequencing based QTL mapping for rice grain yield under reproductive stage drought stress tolerance. Scientific reports 9:14326

39. Lanceras JC, Pantuwan G, Jongdee B, Toojinda T. (2004) Quantitative trait loci associated with drought tolerance at reproductive stage in rice. Plant Physiol 135(1):384-99

40. IRRI (2002) Standard Evaluation System for Rice. International Rice Research Institute, Manila

41. Uga Y, Okuno K, Yano M (2011) Dro1, a major QTL involved in deep rooting of rice under upland field conditions. J Expt Bot 62(8): 2485-2494

42. Reynolds SG (1970) The gravimetric method of soil moisture determination, Part 1 A study of equipments and methodological problems. Journal of Hydrology 11: 258-273

43. Plaschke J, Ganal MW, Röder MS (1995) Detection of genetic diversity in closely related bread wheat using microsatellite markers. Teor Appl Genet 91:1001-1007

44. Panaud O, Chen X, McCouch SR (1996) Frequency of microsatellite sequences in rice (Oryza sativa L.). Genome 38(I):1170-1176

45. Sangeetha A, Malhotra PK, Bhatia VK, Rajendra $P$ (2008) Statistical package for agricultural research (SPAR 2.0). J Indian Soc Agric Stat 62:65-74

46. Wei T, Simko V (2017) R package "corrplot": visualization of a Correlation Matrix (Version 0.84). https://cran.r-project.org/web/packages/corrplot/corrplot.pdf

47. Neuwirth E (2014) Package 'RColorBrewer'. https://cran.rproject.org/web/packages/RColor Brewer/RColorBrewer.pdf.

48. Bradbury PJ, Zhang Z, Kroon DE, Casstevens TM, Ramdoss Y, Buckler ES. (2007) TASSEL: Software for association mapping of complex traits in diverse samples. Bioinformatics 23:2633-2635. 
49. Zhang Z, Ersoz E, Lai CQ, Todhunter RJ, Tiwari HK, Gore MA, Bradbury J, Yu J, Arnett DK, Ordovas JM, Buckler E (2010) Mixed linear model approach adapted for genome-wide association studies. Nat. Genet. 42, 355-360

50. Rincent R, Moreau L, Monod H, Kuhn E, Melchinger A, Malvar RA, Moreno-Gonzalez J, Nicolas S, Madur D, Combes V, Dumas F, Altmann T, Brunel D, Ouzunova M, Flament P, Dubreuil P, Charcosset A, Mary-Huard T (2014) Recovering power in association mapping panels with variable levels of linkage disequilibrium. Genetics 197:375-387

51. Das G, Patra JK, Baek KH (2017) Insight into MAS: a molecular tool for development of stress resistant and quality of rice through gene stacking. Front Plant Sci 8:985

52.

Borevitz JO, Nordborg M (2003) The impact of genomics on the study of natural variation in Arabidopsis. Plant Physiol 132 (2):718-725

53. Balasubramanian S, Schwartz C, Singh A, Warthmann N, Kim MC, Maloof JN, Loudet O, Trainer GT, Dabi T, Borevitz JO (2009) QTL mapping in new Arabidopsis thaliana advanced intercrossrecombinant inbred lines. PLoS One 4 (2):e4318

54. Ibrahim AK, Zhang L, Niyitanga S, Afzal MZ, Zhang L, Zhang L, Qi J (2020) Principles and approaches of association mapping in plant breeding. Tropical Plant Biol 13: 212-224

55. Zhu C, Gore M, Buckler ES, Yu J (2008) Status and prospects of association mapping in plants. The plant genome 1:5-20

56. Pritchard J, Stephens M, Donnelly P (2000) Inference of population structure using multilocus genotype data. Genetics 155:945-959

57. Yu Y, Lee H-O, Chin JH, Park HY, Yoo S-C (2017) The complete chloroplast genome sequence of Oryza sativa aus-type variety Nagina-22 (Poaceae). Mitochondrial DNA Part B: Resources 2(2): 819-20

58. Agrama HA, Eizenga GC, Yan W (2007) Association mapping of yield and its components in rice cultivars. Molecular Breeding 19: 341-356

59. Dixit S, Swamy BPM, Vikram P, Ahmed HU, Cruz MTS, Amante M, Atri D, Leung H, Kumar A (2012). Fine mapping of QTLs for rice grain yield under drought reveals sub-QTLs conferring a response to variable drought severities. Theor Appl Genet 125:155-169

60. Sabar M, Shabir G, Shah SM, Aslam K, Naveed SA, Arif M. (2019) Identification and mapping of QTLs associated with drought tolerance traits in rice by a cross between Super Basmati and IR55419-04. Breeding science 69(1):169-78.

61. Xing Z, Tan F, Hua P, Sun L, Xu G, Zhang Q (2002) Characterization of the main effects, epistatic effects and their environmental interactions of QTLs on the genetic basis of yield traits in rice. Theor Appl Genet 105:248-257

62. Qu Y, Ping M, Hongliang Z, Chen Y, Gao Y, Tian Y, Wen F, Li Z (2008) Mapping QTLs of root morphological traits at different growth stages in rice. Genetica 133:187-200

63. Kamoshita A, Wade LJ, Ali ML, Pathan MS, Zjang J, Sarkarung S (2002) Mapping QTL for root morphology of a rice population adapted to rainfed lowland conditions. Theor Appl Genet 104:880- 
64. Kanagaraj P, Prince K. S. J, Annie Sheeba J, Biji K. R, Sheetal Babu Paul, Senthil A, Chandra Babu R (2010) Microsatellite markers linked to drought resistance in rice (Oryza sativa L.). Current science 98:836-839

65. Swamy MBP, Vikram P, Dixit S, Ahmed HU, Kumar A (2011) Meta-analysis of grain yield QTL identified during agricultural drought in grasses showed consensus. BMC Genomics 12:319

66. Prince SJ, Beena R, Gomez SM, Sentivel S, Babu RC (2015) Mapping Consistent Rice (Oryza sativa) Yield QTLs under Drought Stress in Target Rainfed Environments. Rice8:25

67. Gomez SM, Boopathi NM, Kumar SS, Ramasubramanian T, Chengsong Z, Jeyaprakash P, Senthil A, Babu RC (2010) Molecular mapping and location of QTLs for drought-resistance traits in indica rice (Oryza sativa L.) lines adapted to target environments. Acta Physiol Plant 32:355-364.

68. Zhao XQ, Xu JL, Zhao M, Lafitte R, Zhu LH, Fu BY, Gao YM, Li ZK (2008) QTLs affecting morphophysiological traits related to drought tolerance detected in overlapping introgression lines of rice (Oryza sativa L.). Plant Sci 174(6):618-625

69. Babu RC, Nguyen BD, Chamarerk V, Shanmugasundaram P, Chezhian P, Jeyaprakash P, Ganesh SK, Palchamy A, Sadasivam S, Sarkarung S, Wade LJ, Nguyen HT (2003) Genetic analysis of drought resistance in rice by molecular markers: association between secondary traits and field performance. Crop Sci 43:1457-1469

70. Salunkhe AS, Poornima R, Prince KS, Kanagaraj P, Sheeba JA, Amudha K, Suji KK, Senthil A, Babu RC (2011) Fine mapping QTL for drought resistance traits in rice (Oryza sativa L.) using bulk segregant analysis. Mol Biotechnol. 49(1):90-5

71. Sandhu N, Kumar A (2017) Bridging the rice yield gaps under drought: QTLs genes and their use in breeding programs. Agronomy 7(2):27

72. Zheng HG, Babu RC, Pathan MS, Ali L, Huang N, Courtois B, Nguyen HT (2000) Quantitative trait loci for root-penetration ability and root thickness in rice: comparison of genetic backgrounds. Genome 43(1):53-61

73. Singh S, Pradhan SK, Singh AK and Singh ON (2012) Marker validation in recombinant inbred lines and random varieties of rice for drought tolerance. AJCS 6(4):606-612

74. Zhao Y, Jiang C-H, Rehman RMA, Zhang H-L, Li J, Li Z-C (2019) Genetic analysis of roots and shoots in rice seedling by association mapping. Genes Genomics 41:95-105

75. An H, Liu K, Wang B, Tian Y, Ge Y, Zhang Y, et al. (2019). Genome-wide association study identifies QTLs conferring salt tolerance in rice. Plant Breed139:73-82

76. Xu F, Bao J, He Q, Park YJ (2016) Genome-wide association study of eating and cooking qualities in different subpopulations of rice (Oryza sativaL.). BMC Genomics 17:633

77. Zhong M, Wang L, Yuan J, Luo L, Xu C, He YQ (2011) Identification of QTL affecting protein and amino acid contents in rice. Rice Sci 18(3):187-195 
78. Raju BR, Narayanaswamy BR, Mohankumar MV, Sumanth KK, Rajanna MP, Mohanraju B, Udayakumar M, Sheshshayee MS (2014) Root traits and cellular level tolerance hold the key in maintaining higher spikelet fertility of rice under water limited conditions. Functional Plant Biology 41(9):930-939

79. Courtois B, Audebert A, Dardou A et al. (2013) Genome-wide association mapping of root traits in a japonica rice panel. PLoS One 8:e78037

80. Henry A, Gowda VRP, Torres R, Mcnally K, Serraj R (2011) Variation in root system architecture and drought response in rice (Oryza sativa): Phenotyping of the Oryza SNP panel in rainfed lowland fields. Field Crops Research 120(2): 205-14

81. Gowda, VRP, Henry A, Yamauchi A, Shashidhar HE and Serraj R (2011) Root biology and genetic improvement for drought avoidance in rice. Field Crops Research 122(1):1-13.

82. Wasson AP, Richards RA, Chatrath R, Misra SC, Prasad SV, Rebetzke GJ et al. (2012) Traits and selection strategies to improve root systems and water uptake in water-limited wheat crops. J Exp Bot 63:3485-3498

83. Lynch JP, Brown KM. 2012. New roots for agriculture: exploiting the root phenome. Philosophical Transactions of the Royal Society B - Biological Sciences 367:1598-1604

84. Abd Allah A, Badawy SA, Zayed B, El-Gohary A (2010) The role of root system traits in the drought tolerance of rice (Oryza sativa L.). World Acad Sci Eng Technol 68:1378-1382.

85. Kirkegaard JA, Lilley JM, Howe GN, Graham JM (2007) Impact of subsoil water use on wheat yield. Aust J Agric Res 58:303-315.

86. deDorlodot S, Forster B, Pagès L, Price A, Tuberosa R, Draye X (2007) Root system architecture: Opportunities and constraints for genetic improvement of crops. Trends Plant Sci 12:474-481

87. Phung NTP, Mai CD, Hoang GT et al. (2016) Genome-wide association mapping for root traits in a panel of rice accessions from Vietnam. BMC Plant Biol16: 64

88. Kashiwagi J, Krishnamurthy L, Upadhyaya H, Krishna H, Chandra S, Vadez V, et al. (2005) Genetic variability of drought-avoidance root traits in the mini-core germplasm collection of chickpea (Cicer arietinum L.). Euphytica 146:213-222

89. Guo L, Guo W, Zhao H, Wang J, et al. (2015). Association mapping and resistant alleles' analysis for japonica rice blast resistance. Plant Breed 134: 646-652

90. Zheng H, Wang J, Zhao H, Liu H, Sun J, Guo J, Zou D (2015) Genetic structure, linkage disequilibrium and association mapping of salt tolerance in japonica rice germplasm at the seedling stage. Mol Breeding (2015) 35:152

91. Eizenga GC, Jia MH, Jackson AK, Boykin DL, Ali ML, Shakiba E, Tran NT, McCouch SR, Edwards JD (2019) Validation of yield component traits identified by genome-wide association mapping in a tropical japonica $\times$ tropical japonica rice biparental mapping population. Plant Genome 12:180021

\section{Figures}




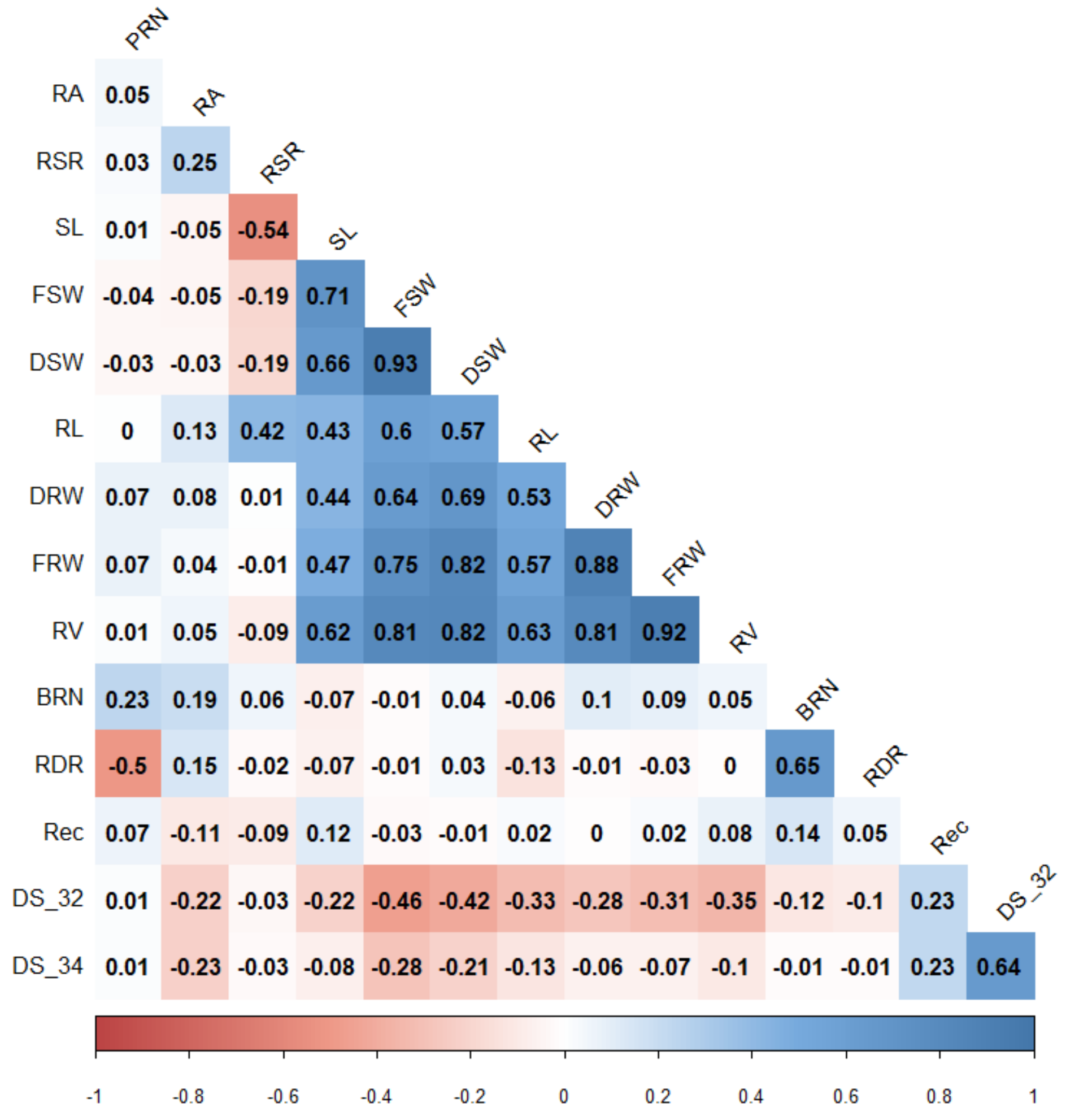

Figure 1

Pearson correlation coefficient between root, shoot and drought tolerance traits in rice 

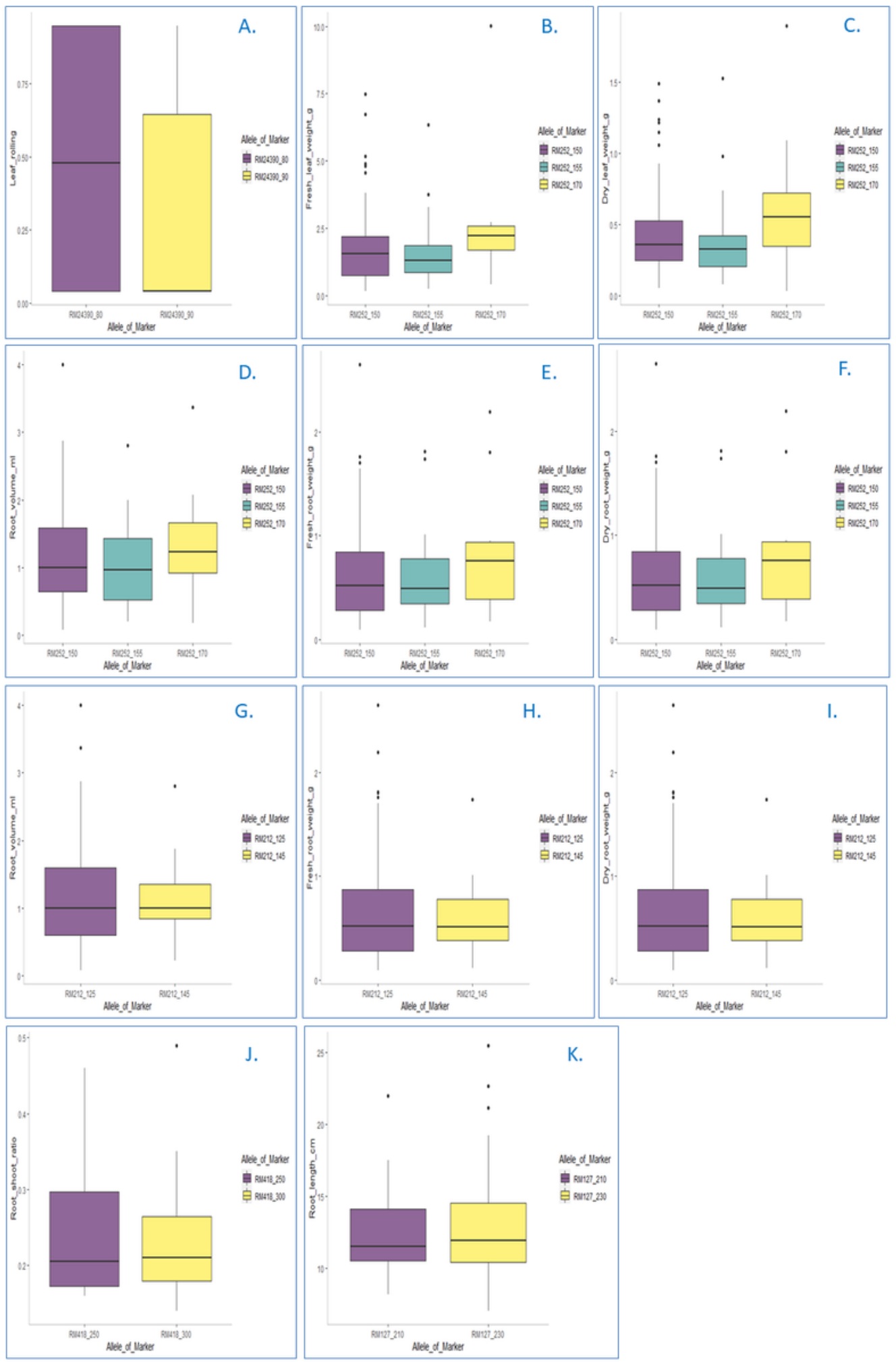

Figure 2

The allelic effects, in terms of band size in bp, of different linked markers 